\title{
Research on Community Respite Service for Disabled Elderly Based on Community Theory
}

\author{
Yajing Sun \\ School of Political Science and Law \\ University of Jinan \\ Jinan, China \\ 814150722@qq.com
}

\author{
Xianhong $\mathrm{Wu}$ \\ School of Political Science and Law \\ University of Jinan \\ Jinan, China \\ 120982579@qq.com
}

\begin{abstract}
Filial piety is a traditional virtue of the Chinese. But for disabled or semi-disabled elderly family, it has become a torture. In the long-term care and supply dislocation, hospitals and commercial institutions have high nursing costs and the cost of care has made most families unable to afford it. This research uses the field investigation and analysis method of social investigation. In addition, it makes a specific statistical analysis of the family situation of some disabled elderly people.This paper makes in-depth research from the perspective of domestic and foreign market demand and difficulties. Besides, it also reveals the practical difficulties of related research. In the end, the author puts forward countermeasures from four aspects: individuals, families, society and government. It combines diversified modes to solve the problems and difficulties of disabled elderly and their family members. To solve the pressure of family care, the research on community respite service for the disabled elderly is particularly important.
\end{abstract}

Keywords-Community Theory; Disabled Elderly; Community Service; Respite Service

\section{RESEARCH BACKGROUND AND SigNIFICANCE}

\section{A. Background}

Statistics show that by the end of 2017, the number of elderly people over the age of 60 has reached 241 million, accounting for $17.3 \%$ of the total population. And the growing at an annual rate of 8 million. [1] By the end of 2015, Jinan City has 1.28 million people aged 60 or above. It is predicted that the total number of elderly people in the city will reach 1.6 million by 2020 , which is $25 \%$ of the total population. According to statistics of the Jinan City Aging Office, In January 2018, Jinan City had approximately 246,000 disabled and partially disabled elderly people, accounting for about $20 \%$ of the elderly population. Due to natural laws, the proportion of disabled and semi-disabled seniors is high. For historical and practical reasons, our country's society presents more and more single-child families. For the only child, the family's elderly are once incapacitated or incapable. Its burden is extremely serious. Families often work hard to increase their "hardships", physically and mentally exhausted, mentally depressed, and even collapse. This status shows that China's current the oldage pension service system has been difficult to satisfy with the current pension needs of our country. On the basis of this, based on the social pension, the new-age pension model.
The so-called "gasp service" is to provide a rest period for family members who have long-term sickness and disability in the care of patients. [2] "Wheezing service" is divided into two modes, namely "home respite" for sending professionals to the sick elderly home for short-term care and "community/institutional wheezing to send sick old people to community care institutions for short-term care". The purpose of these two types of respite services is to enable the families of patients to temporarily liberate from the heavy care and nursing care and relieve the stress.

According to the Notice of the Central Government on the Financial Support for Launching Pilot Work for the Reform of Home- and Community-based Aging Services (No. 200 of the People's Letter [2016]) and the Notice on Launching the Pilot Application for the Reform of Home- and Community-based Aged Care Services in 2016 On the basis of local declarations ([2016] No. 201), the Ministry of Civil Affairs and the Ministry of Finance jointly determined 26 cities (districts) of 20 provinces and municipalities. Home and community pension reform service pilot area and this is also the starting point document of the central policy document on the "pilgrimage service" officially launched, which laid the foundation for the implementation of our "breathing service".

\section{B. Social Significance and Impact}

The increasing social reality background of China's rapidly growing and disability families reflects a wide range of social welfare implications in solving related issues at different levels. In short, 'there is a problem for the nation, and for people to worry about."

\section{1) National level}

This study is aimed at the group of elderly persons with disability and carries out certain supplements to the universal social welfare implemented at the national level. And it makes up for some aspects of the country's macro-level social welfare that have not been taken into consideration. It is helpful to assist or fill in some missing functions that the relevant government departments have not paid attention to or have done to the group.

\section{2) Social level}

By providing social benefits to the group and its families to have a better life. It reflects the principle of mutual benefits of social welfare, which is conducive to solving the problems 
caused by the increasingly severe aging in China. On the other hand, it will reduce the social burden, and build a harmonious society. To cultivate community residents' sense of acceptance of disabled seniors and the spirit of helping disabled elderly, and to build a social environment that respects and cares for disabled elderly people, thus forming a communicative and harmonious community.

\section{3) Family level}

Relieves the mental stress of disabled or disabled family caregivers, enhances their self-confidence in life and promotes family harmony. The development of service projects can improve the efficacy and self-confidence of the clients and promote their social integration capabilities. At the same time, they can increase their own positive energy when implementing services for disabled seniors, realize "helping others to help themselves", and promote their own independent future life. The problems and challenges faced.

\section{The TheORETICAL BAsis}

\section{A. Community Theory}

[3]Ferdinand Tnnies(1855-1936) believes that the community is a naturally formed group in human society and is built on the common memory related to the human instinct of the person concerned or the habitual or restrictive adaptation or thought. The space all personnel should help each other, share responsibility, and realize the harmonious development of the community.

According to the community theory, family caregivers of disabled or partially disabled old people in the community are under enormous physical and psychological pressure due to long-term care. This article takes the perspective of the community as a perspective to help disabled family mutual assistance services and volunteer operation mechanisms. It relies heavily on the self-help and mutual assistance study of residents in the community. In addition, the idea of community service based on mutual assistance and mutual cooperation is not only conducive to its continuous good care, but also helps the community to help each other and build community with mutual help, close contact, and human feelings.

\section{B. Respite Service Theory}

[4]Respite Care originated in 1970 and appeared in the United States. Chinese translations include respite services and temporary care. This is an intervention designed to provide support to informal caregivers to temporarily ease the burden of care to enhance or restore their ability to re-provide care. Griffith proposes that the services of the respite service are long-term caregivers and provide short-term care for the primary caregiver by providing temporary care services. [5]

\section{THE QUESTION Is RAISED}

\section{A. Care of disabled seniors}

The research data shows that as of the end of 2017, the population aged 60 and above in China has reached 241 million, accounting for $17.3 \%$ of the total population. Among them, in 2016, nearly 40 million people were disabled and half disabled.
From 2005 to 2050, the number of disabled people in China will increase from 21.73 million to 70.776 million. The care of disabled and demented elderly people who need long-term care has become a major social issue that needs to be resolved.

\section{B. Market Analysis}

1) Analysis of domestic industry needs

Home-based care is the first choice of old-age care for the majority of elderly people in China. As the main force for the long-term care of the elderly, family caregivers take great care in all aspects of care. At present, home-based respite services are mainly provided by home-based care for the elderly. The country and the Taiwan region of China are developing well. The domestic mainland region first conducted pilot work in local areas in Hangzhou in 2011. However, at present, there are relatively few practices related to domestic home respite services.

The needs of caregivers: The cognitive deterioration of disabled elderly people and the existence of mental and behavioral problems getting worse. That is the level of disability is getting higher and higher, related medical services are not in place, and care is also greatly increased. For example, workers who take care of the elderly with dementia are often tossed by the patient's behavioral problems to the brink of collapse. And China is currently lacking supportive respite services for home caregivers of such patients.

The social support needs of family caregivers for disabled elderly people mainly include the following: disability old people, caregivers' human resources, economic resources of caregivers. And livelihood pressure of caregivers, physical and mental health is also important. Family caregivers have strong demand for respite services and on-site services. The role of social resources relying on community and relative resources in respite services needs to be strengthened.

\section{2) Prominent problems in domestic breathing service} industry

In China's mainland areas, there are widespread problems with service coverage, lack of time, and flexibility. In addition, China's home-based respite service is still at a pilot stage. To truly alleviate the long-standing pension problems in China, it is necessary to improve its service model as soon as possible and carry out extensive promotion to improve the accessibility and applicability of services and effectively help solve the problems facing home-based care for the elderly. At present, the promotion of home-based respite services in the Mainland still faces the following problems.

\section{3) Lack of funds}

At present, the funds needed in the pilot areas in China are only supported by local government finances, and their sources are single. As the elderly population increases year by year, the number of elderly people who need long-term care is gradually increasing. A single government subsidy cannot be a long-term solution. For economically underdeveloped areas, this move will not be able to benefit more people. Therefore, the funding issue is the bottleneck of our current promotion of home-based respite services. For the developing countries that have increasingly outstanding pension problems, they can learn from 
the government's purchase of integrated commercial insurance, social charity organizations' involvement, and personal expenses. Besides, clearly define the service time limit and service content within the scope of government procurement and provision of services are also play significant roles in this phenomenon. For those who have other needs, they can undertake corresponding services at their own expense, thus providing a new way for the operation of funds for home-based respite services.

\section{4) Lack of policy guidance}

[5]Home-based respite services catered to the current pension pattern of " 9073 " (90\% elderly people living at home, $7 \%$ community pension, and 3\% institutional pensions). This has injected fresh blood into the development of the homebased pension system, but there is still a lack of home-based respite services. At present, developed areas in mainland China such as Hangzhou, Shanghai, Guangzhou, and Beijing have started trials for home-based respite services. It is therefore urgent to investigate the status of current pilot areas, summarize trial experience, and improve the home-based respite service system in each region.

\section{5) Others}

In addition to the above two aspects, the application conditions for domestic home respite services, access qualifications for service providers. And it has not been uniformly standardized. In the future, The establishing a sound home-based respite service related policy system and opening up this source funding support, which focuses on government purchases services should be carried out around the caregiver .The care recipients, step up publicity efforts, and timely adjust service content and develop services based on flexible assessment of the needs and utilization of both parties. The personnel access system will increase the flexibility of service time, effectively help relieve the burden on home caregivers, improve the quality of life of caregivers, promote family harmony, and provide new ideas for solving the pension problem.

\section{Practical Difficulties and Solutions}

\section{A. Realistic difficulties faced by traditional old-age care}

After surveying 253 families of disabled seniors in the community of the "Li xia" District, Jinan City, Shandong Province, they conducted a questionnaire survey on the "Basic Needs of Incapacitated Elderly Caregivers" and learned that the families of disabled elderly people in this community are mainly facing difficulties:

\section{1) Personallevel}

The main caregivers of disabled elders are older, have insufficient capacity for care and are under tremendous physical and psychological pressure. According to the survey, $51 \%$ of caregivers are over 50 years old, and $85 \%$ of caregivers consider High mental pressure, 21\% strong feeling of powerlessness;

\section{2) Community level}

The main caregivers of the disabled elderly feel the pressure from the community. The support network is insufficient, and $25 \%$ of the caregivers in the survey stated that they are suffering from the strange eyes of the society;

\section{3) At the family level}

The main caregivers of the disabled elderly bear economic pressures for the disabled elderly and families. And 62\% of caregivers indicate that it is difficult to support the rehabilitation costs of the disabled elderly;

In summary, the families of disabled elderly people have been subjected to multiple psychological, community, and economic pressures during the care process.

\section{B. The solution to the problem}

1) Personal level:

Under the current system, the family members of the disabled are constrained by heavy economic, rehabilitation, and spiritual burdens. It also has rarely received support and participates in social life. Conducting social worker services for the family members of the disabled can help alleviate their psychological pressure and obtain social support.

\section{2) At the family level}

The miniaturization of the family makes it difficult for the family members of the disabled to take care of the handicapped. It provides various educations and training activities for the family members of the disabled, helps build a support network. And it can also improve their ability to care. Better service for the handicapped, at the same time, it will relieve the burden of caring for the handicapped and promote the stability and harmony of the family;

\section{3) Community level}

Strengthen volunteer cultivation and go deep into the core work to increase the professionalism of volunteer teams, further expand the team size. Besides, the increase the range of basic free welfare services so that more disabled elderly and their families can benefit. Through the professional relationship established between the organization and the service object, the organization forms different levels of demand networks based on the information files and databases that have been continuously established in the development of the organization. Each jurisdiction has formed a network of information and communication mechanisms to help disabled elderly caregivers. Through the implementation of the project, the community residents can pay more attention to and understand this group, actively participate in the activities of helping them. It can create a community environment that understands the care of the family members of the disabled and forms a community-level social support network. Expand the scope of aid groups and services.

\section{4) At the government level}

First, the government will provide necessary support for the development of breathing services in policy formulation and economic support in light of its own economic strength and willingness to serve, which strive to play a leading role for the government in breathing services. Second, at the institutional level, the exploration and establishment of a long-term care insurance system is the fundamental solution to the care and wheezing services of disabled elderly people. Finally, in the 
government's responsibilities and policies, the relevant safeguard policies and supervision are improved.

\section{CONCLUSION}

The final research results of this study show that in the aspect of community support, it is necessary to have a better understanding of the various needs of elderly families through the close links between community residents and disabled elderly people. In terms of staff education and counseling, social workers have organized personnel to form an education group and a support group to provide skills training and psychological counseling to the staff respectively. For family support, the family members should give full trust and support to the caregivers, and the family members of the elderly should answer the staff's questions in a timely manner. In disability services, the disabled and semi-disabled elderly are given short-term care in cooperation with professional social work organizations to provide breathing space for their families.

\section{REFERENCES}

[1] Bi Xiaozhe. "Wheezing Service" Helps "Family Endowment" [N]. China Business Daily, 2015-05-08P02.(In Chinese)

[2] Yu Xuchu."Wheezing service" is a humane move [N]. Family doctor reported that 2017-08-21001. (In Chinese)

[3] Li meng.The constitution of "society": natural law and the basis of modern social theory [J]. Chinese social science,2012(10):87-106+206207. (In Chinese)

[4] Wang shang, li shan. The development of foreign respite service and its enlightenment to China's home-based nursing [J]. Journal of northeast normal university (philosophy and social science edition),2014(06)

[5] Chen Jihua, Ruan Haiqin. Research on family care for elderly people with impaired access to impaired services under social support theory[J]. Economic Research Guide, 2018(07):60-66. (In Chinese)

[6] Zheng jie. Shanghai community endowment policy under the "9073" pattern -- from the perspective of network community model [J]. Journal of tianshui institute of administration, 2014, 15(06):36-41. (In Chinese) 